\title{
Correction to: A Comparative View of Reported Adverse Effects of Statins in Social Media, Regulatory Data, Drug Information Databases and Systematic Reviews
}

\author{
Su Golder ${ }^{1}$ D $\cdot$ Karen Smith $^{2} \cdot$ Karen O'Connor $^{3} \cdot$ Robert Gross $^{3} \cdot$ Sean Hennessy ${ }^{3} \cdot$ Graciela Gonzalez-Hernandez $^{3}$
}

Published online: 15 January 2021

๑) Springer Nature Switzerland AG 2021

\section{Correction to: Drug Safety https://doi.org/10.1007/s40264-020-00998-1}

The article A Comparative View of Reported Adverse Effects of Statins in Social Media, Regulatory Data, Drug Information Databases and Systematic Reviews, written by Su Golder, Karen Smith, Karen O'Connor, Robert Gross, Sean Hennessy, Graciela Gonzalez-Hernandez, was originally published electronically on the publisher's internet portal on 01 October 2020 without open access. With the author(s)' decision to opt for Open Choice the copyright of the article changed on 17 December 2020 to () The Author(s) 2020 and the article is forthwith distributed under a Creative Commons Attribution NonCommercial 4.0 International License, which permits any non-commercial use, sharing, adaptation, distribution and reproduction in any medium or format, as long as you give appropriate credit to the original author(s) and the source, provide a link to the Creative Commons licence, and indicate if changes were made. The images or other third party material in this article are included in the article's Creative Commons licence, unless indicated otherwise in a credit line to the material. If material is not included in the article's Creative Commons licence and your intended use is not permitted by statutory regulation or exceeds the permitted use, you will need to obtain permission directly from the copyright holder. To view a copy of this licence, visit http://creativecommons .org/licenses/by-nc/4.0/".

Su Golder

su.golder@york.ac.uk

Karen Smith

ksmith003@regis.edu

Karen O'Connor

karoc@pennmedicine.upenn.edu

Robert Gross

grossr@pennmedicine.upenn.edu

Sean Hennessy

hennessy@pennmedicine.upenn.edu

Graciela Gonzalez-Hernandez

gragon@pennmedicine.upenn.edu

1 NIHR Postdoctoral Research Fellow, Department of Health Sciences, University of York, York YO10 5DD, UK

2 Regis University School of Pharmacy, Denver, CO, USA

3 Department of Biostatistics, Epidemiology and Informatics, Perelman School of Medicine, University of Pennsylvania, Philadelphia, PA, USA 